\title{
Multiple Activities Associated with the Capsid Protein of Satellite Panicum Mosaic Virus Are Controlled Separately by the $\mathrm{N}$ - and $\mathrm{C}$-Terminal Regions
}

\author{
Dong Qi and Karen-Beth G. Scholthof \\ Department of Plant Pathology and Microbiology, Texas A\&M University, College Station 77843-2132, U.S.A.
}

Submitted 7 December 2007. Accepted 19 December 2007.

The 17-kDa capsid protein (CP) of satellite panicum mosaic virus (SPMV) contains a distinct $\mathrm{N}$-terminal argininerich motif (N-ARM) which is required for SPMV virion assembly and the activity of SPMV CP to promote systemic accumulation of its cognate RNA. The present study indicates that SPMV CP also is involved in SPMV RNA accumulation in inoculated leaves and that this activity is also dependent on a functional N-ARM. In addition, deletions of a C-terminal region abolish virion assembly and impair SPMV RNA accumulation in both inoculated and systemic leaves. Unlike the N-ARM mutations, substantial deletions of the SPMV CP C-terminus do not affect SPMV RNA binding activity. Interestingly, SPMV CP also binds Panicum mosaic virus genomic RNA via N-ARM-mediated CP:RNA interactions. Mutations of the N-ARM and the Cterminal regions significantly reduce SPMV CP titers and result in symptom attenuation. In contrast, virions were not associated per se with symptom exacerbation or successful SPMV RNA accumulation. The results show the existence of a correlation between $\mathrm{N}$ - and $\mathrm{C}$-termini-mediated contributions for $\mathrm{CP}$ accumulation, symptom induction, defective-interfering RNA accumulation, and temperature sensitivity of SPMV RNA maintenance. The data provide further evidence that SPMV CP has multiple roles during infection, which might involve the formation of nonvirion CP:RNA complexes whose stability is controlled in a biologically relevant manner by the $\mathrm{N}$ - and $\mathrm{C}$-termini of the CP.

The mixed infection of Panicum mosaic virus (PMV) and satellite panicum mosaic virus (SPMV) is the cause of St. Augustinegrass decline disease (Scholthof et al. 1999). SPMV depends on its helper virus PMV (genus Panicovirus; family Tombusviridae) for replication as well as systemic movement in host plants (Masuta et al. 1987; Scholthof et al. 1999). PMV has the unique feature of supporting the multiplication of two distinct subviral agents, SPMV and a satellite RNA (Cabrera and Scholthof 1999). PMV has a positive-sense, singlestranded genomic RNA (gRNA) of 4,326 nucleotides (nt), which encodes six open reading frames (ORF) (Turina et al. 1998). The p48 and p112 proteins are required for replication and proteins are expressed directly from the gRNA (Turina et

Corresponding author: K.-B. G. Scholthof; Telephone: +1.979.845.8265; Fax: +1.979.845.6483; E-mail: kbgs@ $@$ tamu.edu

*The $\boldsymbol{e}$-Xtra logo stands for "electronic extra" and indicates two supplemental figures are published online. al. 1998). The 26-kDa capsid protein (CP) and three smaller proteins (p8, p6.6, and p15) are translated from a single subgenomic RNA (sgRNA). These proteins are required for local and systemic movement of PMV in millet plants (Turina et al. 2000). Compared with the mild symptoms associated with PMV infection alone, a mixed infection of PMV and SPMV induces exacerbated symptoms, including a severe chlorotic mottle with bleaching effects, stunting, and failure to set seed (Scholthof 1999).

SPMV has a positive-sense, single-stranded RNA genome of $824 \mathrm{nt}$ which encodes a $17-\mathrm{kDa} \mathrm{CP}$ to assemble 16-nm T = 1 icosahedral satellite virus particles (Ban and McPherson 1995; Masuta et al. 1987; Qiu and Scholthof 2000). Several cis-acting elements involved in replication and movement were identified within the 5' untranslated region (UTR) and 3' UTR of SPMV gRNA (Omarov et al. 2005; Qiu and Scholthof 2000). Interestingly, the SPMV CP ORF contains four in-frame start codons on the gRNA and more than one of them can be recognized for translation in vitro as well as in vivo (Omarov et al. 2005). In addition to SPMV gRNA encapsidation, SPMV CP is implicated in symptom exacerbation in millet plants (Qiu and Scholthof 2001; Scholthof 1999). Although SPMV CP is not absolutely required for SPMV RNA replication and systemic movement (Qiu and Scholthof 2000), the absence of CP stimulates the rapid accumulation of SPMV defective interfering RNAs (DIs) (Qiu and Scholthof 2001). In contrast, the presence of full-length CP greatly enhances systemic SPMV RNA accumulation (Omarov et al. 2005). Though multiple biological roles have been reported for SPMV CP, the precise mechanisms behind these functions remain largely unknown.

SPMV CP has a distinct N-terminal arginine-rich motif $(\mathrm{N}$ ARM), which is predicted to extend into the interior of virions to interact with the SPMV gRNA (Ban and McPherson 1995; Makino et al. 2006). This was confirmed by our recent findings that N-ARM mutants are defective in RNA binding and virion assembly, impair systemic SPMV RNA accumulation, and lead to rapid accumulation of SPMV DIs (Qi 2007). Collectively, these results suggested that the N-ARM-mediated SPMV CP:RNA interactions are indispensable for all the reported biological functions associated with SPMV CP.

The present study was initiated to investigate the contribution of additional regions of SPMV CP and to refine the biological role of the N-ARM during local versus full systemic infection. The results show that mutations in the $\mathrm{C}$-terminal region (CTR) reduced SPMV RNA and CP titers in systemically infected leaves, stimulated the accumulation of DIs, attenuated symptoms, and impaired virion formation even though in vitro RNA binding activity was solely controlled by the N-ARM. Both N-ARM and CTR mutants accumulated poorly in inocu- 
lated leaves, yet replication in protoplasts occurred effectively, providing evidence for an ancillary role of SPMV CP in cellto-cell movement. We also observed that the N-ARM and CTR mutants were temperature sensitive, because increased ambient temperature resulted in decreased SPMV CP and RNA in infected plants. Combined with previous data, the results strongly suggest that SPMV CP has multiple roles during infection, including cell-to-cell movement by nonvirion CP:RNA complexes. The stability of these complexes seems to be controlled in a biologically relevant manner by viral RNA:CP and alternative $\mathrm{CP}$-mediated interactions that are separately regulated by the $\mathrm{N}$ - and $\mathrm{C}$-termini of the $\mathrm{CP}$. In vitro PMV RNA binding activity of the SPMV CP suggests that the formation of such complexes comprising, alone or in combination, SPMV CP, PMV RNA, and other PMV- or host-encoded factors may account for the synergistic interactions between PMV and SPMV in coinfections (Scholthof 1999).

\section{RESULTS}

\section{Biological activity of SPMV mutants.}

To elucidate the functional mechanisms of SPMV CP contributions to infection, various mutations were introduced at different sites of the SPMV CP ORF (Fig. 1A). Mutants R7/8, $\mathrm{R} 7-12,82 \mathrm{~F}, 130 \mathrm{D}$, and $\Delta \mathrm{C} 6$ have been partially characterized (Qi 2007). In brief, the arginine (R) codons of amino acid residues 7 and 8 were replaced with a serine and alanine codon, respectively, in mutant R7/8. Mutant R7-12 was created based upon R7/8 and contains the additional substitutions of arginine codons at amino acids 11 and 12 with a serine and alanine codon, respectively. Mutant $82 \mathrm{~F}$ contains an in-frame insertion of a six-amino-acid FLAG epitope (DYKDDD) between amino acids 82 and 83. Mutant 130D contains the substitution of the serine codon at the amino acid residue 130 with an aspartic acid codon. Mutants $\Delta \mathrm{C} 6$ and $\Delta \mathrm{C} 9$ have truncations of the last six and nine amino acids, respectively, by introducing premature stop codons on the SPMV CP ORF. Three residues (alanine, proline, and serine) from 149 to 151 were deleted in the mutant $\triangle \mathrm{C}$-APS. The seven SPMV derivatives direct the synthesis of SPMV CP products of predicted sizes as efficiently as SPMV wild-type (WT) in a wheat germ extract in vitro translation system (Fig. 1B). Based on X-ray crystallographic analysis of SPMV CP (Ban and McPherson 1995), the N-ARM plunges into the interior of virions where it engages the SPMV gRNA (Fig. 1C). Amino acids 82, 130, and the last nine amino acids are all within loop regions and not essential for the general "jelly-roll" structure of SPMV CP (Fig. 1C).

Uncapped transcripts of each SPMV derivative and PMV transcripts were inoculated onto proso millet plants (Panicum miliaceum cv. Sunup) and the inoculated plants were maintained in a growth chamber. An infection of PMV alone caused mild chlorotic mottle and a barely visible vein-clearing on infected leaves (Fig. 2). In contrast, plants coinfected with PMV+SPMV developed a typical chlorotic mottle with bleaching effects (Table 1; Fig. 2) and severe stunting (data not shown). Among the seven mutants analyzed in this study, 82F, 130D, and $\Delta$ C6 induced a chlorotic mottle similar to SPMV WT (Fig. 2;

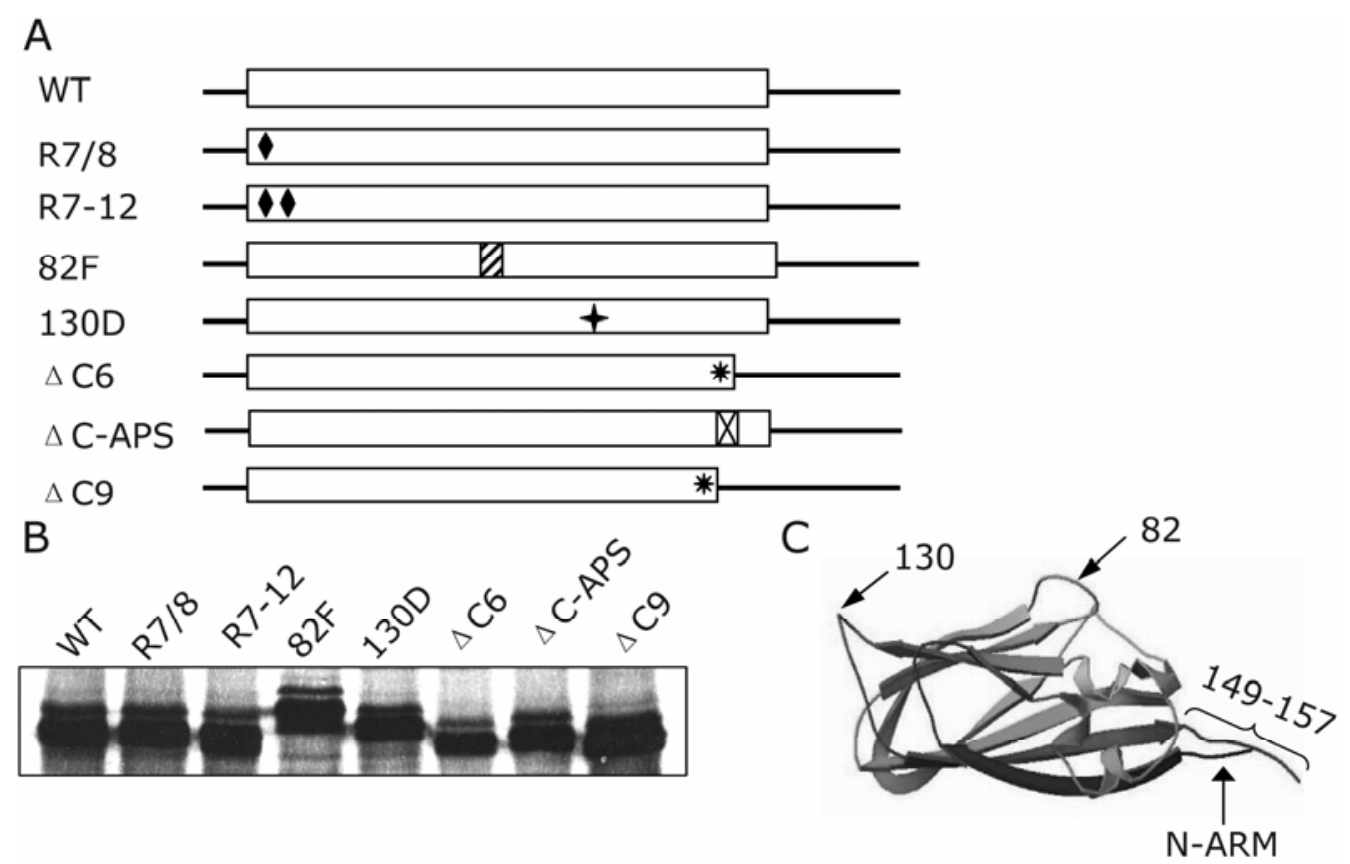

Fig. 1. Schematic representations and in vitro translation analysis of satellite panicum mosaic virus (SPMV) derivatives. A, Schematic representations of the SPMV cDNA constructs. SPMV capsid protein (CP) open reading frame is indicated by the open box. WT represents the SPMV type strain. Mutant R7/8 represents the exchange of arginine codons at the amino acid residues 7 and 8 for serine and alanine (indicated by a diamond). Mutant R7-12 has the additional exchange of arginine codon at amino acid residues 11 and 12 for serine and alanine (indicated as double diamonds). Mutant $82 \mathrm{~F}$ contains the coding sequence (striped box) of a FLAG epitope (DYKDDD) inserted in-frame between the codons of amino acid residues 81 and 83 of SPMV CP, and mutant $130 \mathrm{D}$ is created by substituting the serine at amino acid residue 130 with an aspartic acid (star). Mutants $\Delta \mathrm{C} 6$ and $\Delta \mathrm{C} 9$ represent the truncations of the last six codons and the last nine codons, respectively, which were performed by introducing premature stop codons (asterisks) at the relevant positions. Mutant $\triangle \mathrm{C}$-APS contained the deletion of amino acid codons of 149 to 151 , which is indicated by a crossed box. B, In vitro translation assays of SPMV derivatives illustrated in A using a transcription-translation coupled wheat germ extract system. All tested constructs direct the translation of proteins with predicted sizes. SPMV WT, R7/8, R7-12, and 130D produce proteins of $17 \mathrm{kDa}$. Mutant 82F directs the synthesis of a protein with a molecular weight slightly higher than $17 \mathrm{kDa}$. Mutants $\Delta \mathrm{C} 6, \Delta \mathrm{C}$-APS, and $\Delta \mathrm{C} 9$ produce proteins of different molecular weights, all lower than $17 \mathrm{kDa}$. All proteins are [ $\left.{ }^{35} \mathrm{~S}\right]-\mathrm{methionine}$ labeled and detected by autoradiography. Designation of WT SPMV and each mutant is listed below the blot. C, Spatial distribution of mutated regions on SPMV CP. The original X-ray crystallography analysis was accomplished by Ban and McPherson (1995). Amino acid residues 82 and 130 are indicated by arrows. The last nine amino acid residues are indicated by the bracket. The N-terminal arginine-rich motif (N-ARM) is composed of the first 16 amino acids. Its detailed structure has not been completely resolved. Therefore, the N-ARM with an arrow represents the predicted structural placement. 
Table 1) and stunting. Plants coinfected with PMV $+\Delta C 9$ displayed a mild mottle almost indistinguishable from that caused by PMV infection alone (Fig. 2). Compared with the severe chlorotic mottle caused by SPMV WT and the mild mottle caused by $\Delta \mathrm{C} 9$, mutants R7/8, R7-12, and $\Delta \mathrm{C}$-APS induced leaf symptoms of intermediate levels (Fig. 2; Table 1) but no obvious stunting.

\section{Replication and encapsidation of SPMV CP derivatives.}

To delineate the potential causes for the symptom attenuation by mutations in the N-ARM and CTR, we first evaluated the replication competency of our SPMV mutants. Transfection of foxtail millet protoplasts with transcripts of PMV and each of mutants R7/8, R7-12, $\Delta \mathrm{C}$-APS, and $\Delta \mathrm{C} 9$ led to signifi- cant accumulation of progeny RNA after approximately $48 \mathrm{~h}$ of incubation in a growth chamber (Fig. 3A). Each of these four mutants replicated in protoplasts to a level similar to that of SPMV WT, except that the RNA titer of $\triangle \mathrm{C}$-APS was approximately 20\% lower than SPMV WT (Fig. 3A). Therefore, the symptom attenuation observed for R7/8, R7-12, $\Delta \mathrm{C}$-APS, and $\Delta \mathrm{C} 9$ (Fig. 2) should not be attributed to possible replication defects. DI RNAs were not observed in association with these mutants, in contrast to in planta RNA accumulation analyses (Fig. 4). Mutants 82F, 130D, and $\Delta \mathrm{C} 6$ also were tested for their replication efficiency in foxtail millet protoplasts, with similar results (data not shown).

Encapsidation assays were performed as previously described (Qiu and Scholthof 2001). As predicted, PMV virions
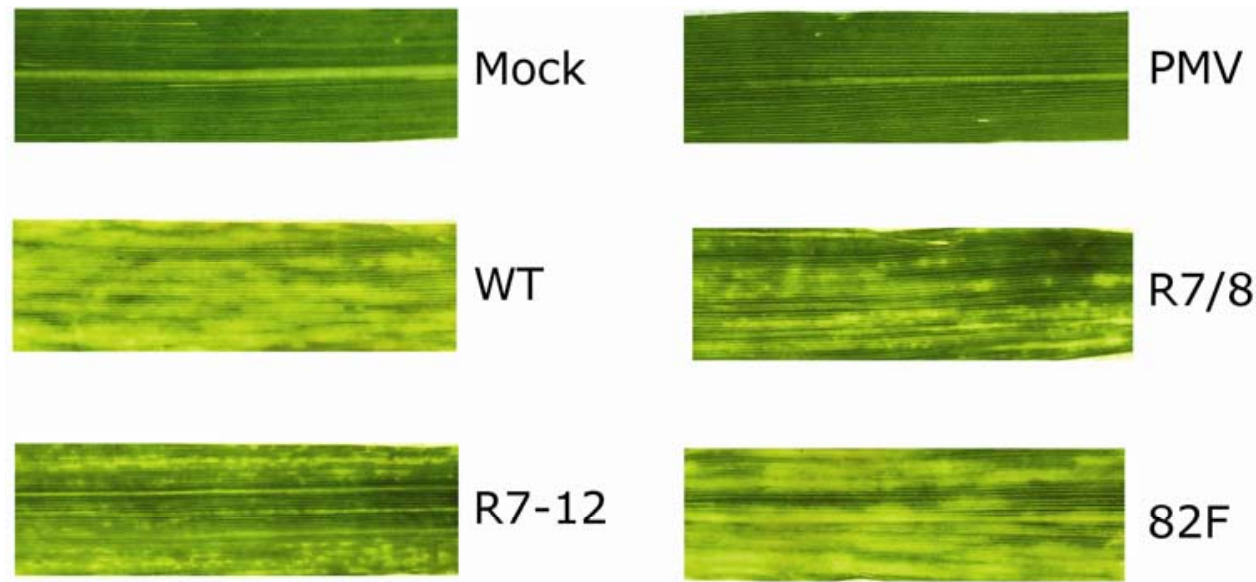

$82 \mathrm{~F}$
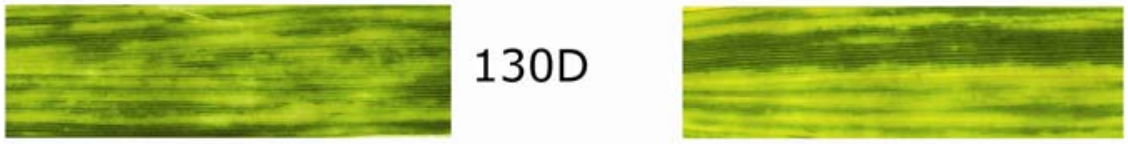

$\triangle \mathrm{C6}$

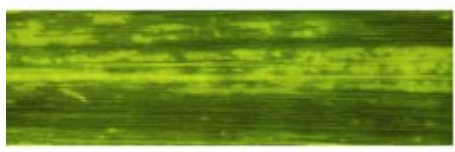

$\triangle \mathrm{C}-\mathrm{APS}$

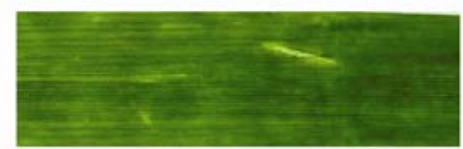

$\triangle \mathrm{C} 9$

Fig. 2. Phenotypic comparison of symptom severity induced by satellite panicum mosaic virus (SPMV) wild-type (WT) and its mutants. Upper systemic leaves from proso millet plants (Panicum miliaceum cv. Sunup) coinfected with Panicum mosaic virus (PMV) and respective SPMV derivatives are monitored and scored for symptom severity. PMV-infected and mock-inoculated plants are included as controls. All leaves are harvested and photographed 3 weeks postinoculation.

Table 1. Phenotype summary of satellite panicum virus (SPMV) wild type and mutants

\begin{tabular}{|c|c|c|c|c|c|c|}
\hline Construct & $\mathbf{R N A}^{\mathbf{a}}$ & Virion $^{b}$ & RNA binding ${ }^{\mathrm{c}}$ & High temperature sensitivity ${ }^{d}$ & Chlorosis $^{\mathrm{e}}$ & CP titer $^{f}$ \\
\hline SPMV & $* * * * *$ & + & + & - & $* * * * *$ & $* * * * *$ \\
\hline $\mathrm{R} 7 / 8$ & */DI & + & - & + & $* *$ & $* *$ \\
\hline R7-12 & $* / \mathrm{DI}$ & - & - & + & $* *$ & $* *$ \\
\hline $82 \mathrm{~F}$ & $* * * * *$ & - & + & - & $* * * * *$ & $* * * * *$ \\
\hline 130D & $* * * * *$ & - & + & - & $* * * * *$ & $* * * * *$ \\
\hline$\Delta \mathrm{C} 6$ & $* * * * *$ & + & + & - & $* * * * *$ & $* * * * *$ \\
\hline$\Delta \mathrm{C}$-APS & $* * * / \mathrm{DI}$ & - & + & + & $* * *$ & $* * *$ \\
\hline$\Delta \mathrm{C} 9$ & $* * / \mathrm{DI}$ & - & + & + & $*$ & $*$ \\
\hline
\end{tabular}

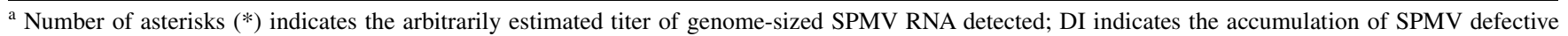
interfering RNAs.

${ }^{\mathrm{b}}$ Symbols + and - indicate the presence or absence, respectively, of SPMV virions on the agarose gels analyzed for encapsidated SPMV RNA.

${ }^{\mathrm{c}}$ Symbols + and - indicate the presence or absence, respectively, of SPMV RNA-binding activity. The lack of SPMV RNA binding in mutants R7-12 is deduced from capsid protein (CP)-derivative NHA. Mutants 82F and 130D were tested previously (D. Qi, R. T. Omarov, and K.-B. G. Scholthof, unpublished data). The binding activities of mutants $\Delta \mathrm{C} 6, \Delta \mathrm{C}$-APS, and $\Delta \mathrm{C} 9$ are predicted based upon SPMV CP deletion derivative $\mathrm{D}$.

${ }^{\mathrm{d}}$ Symbols + and - indicate whether or not high-temperature treatment affected the viral RNA accumulation of SPMV wild-type and derivative mutants.

${ }^{\mathrm{e}}$ Number of asterisks $\left(^{*}\right)$ indicates the arbitrarily estimated leaf symptom severity of infected plants.

${ }^{\mathrm{f}}$ Number of asterisks (*) indicates increasing relative titers of SPMV CP in plants following coinfection with Panicum mosaic virus. 
were present in all infected plants and SPMV virions were detected for SPMV WT (Fig. 3B). Among the seven tested mutants, virions were detected for $\mathrm{R} 7 / 8$ and $\Delta \mathrm{C} 6$ but were not for mutants R7-12, 82F, or 130D (Fig. 3B, upper panel) (unpublished data). Interestingly, $\Delta \mathrm{C}$-APS and $\Delta \mathrm{C} 9$ also were defective in virion assembly (Fig. 3B), though the C-terminal extremity of SPMV CP is predicted to be not essential for its "jelly-roll" core structure (Ban and McPherson 1995). Densitometric analysis using NIH ImageJ indicated that the virion titers of R7/8 and $\triangle$ C6 were approximately $35 \%$ lower than that of SPMV WT. In addition, we consistently detected SPMV RNA encapsidated into PMV virions as SPMV RNA-specific signals comigrating to the position of PMV virions (Fig. 3B), as previously reported (Qiu and Scholthof 2001). In summary, the encapsidation study indicates that the C-terminus of SPMV CP is of crucial importance for SPMV virion assembly despite its dispensability for the core structure of SPMV CP. Because 82F and 130D induced typical chlorotic mottle symptoms associated with SPMV infections (Fig. 2) but were incapable of virion formation, it is evident that SPMV virions or the process of virion assembly is not essential for symptom modulation (Table 1). Although we regard it as unlikely, we cannot rule out the possibility that some of the tested mutants may form virus-like particles that are too unstable to be purified and analyzed using whole-virion gel assays.

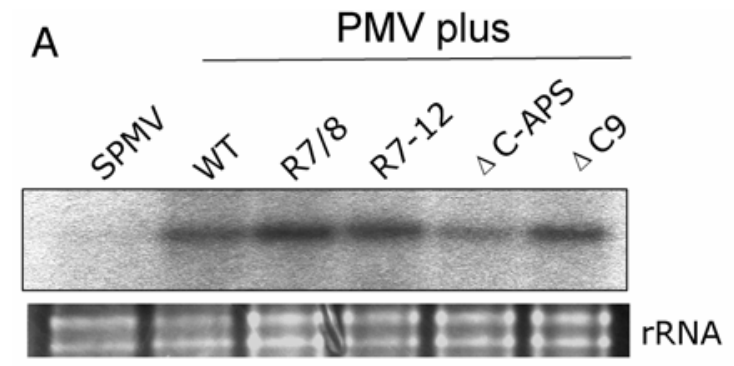

B

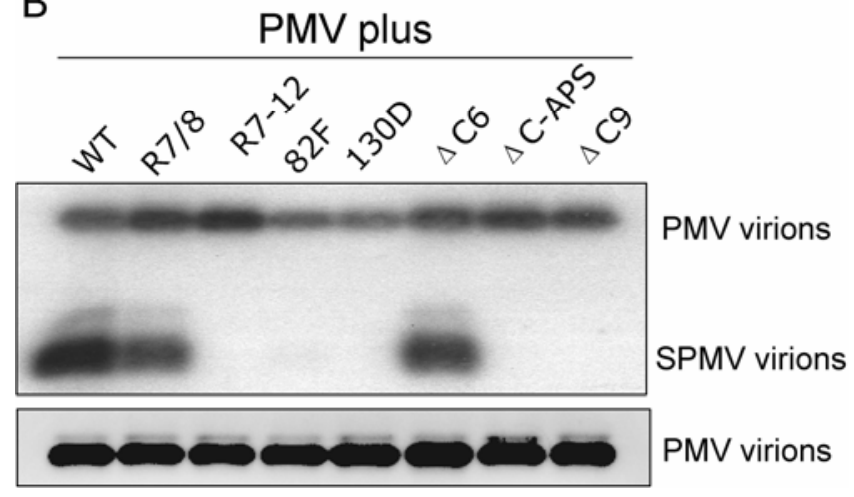

Fig. 3. Replication and encapsidation assays of satellite panicum mosaic virus (SPMV) mutants. A, Replication competency assays of SPMV wildtype (WT) and derivative mutants. Foxtail millet protoplasts were cotransfected with Panicum mosaic virus (PMV) plus WT SPMV or each mutant, as designated above each panel. Protoplasts transfected with SPMV alone is included as the negative control. Total RNA was extracted approximately 48 $\mathrm{h}$ posttransfection. An ethidium-bromide-stained agarose gel is included as the loading control. B, Encapsidation assay of SPMV derivatives using whole virion gels. Encapsidated RNAs were transferred to nylon membrane followed by detection with ${ }^{32} \mathrm{P}$-labeled SPMV cDNA-specific probe (upper panel). The positions of PMV and SPMV virions are indicated on the right side of the panel. SPMV-specific RNAs migrate to the positions of both PMV virions and SPMV virions if present. The ethidium-bromide-stained gel is included as a negative image to demonstrate the presence of PMV virions in all infected proso millet plants (lower panel). Designation of SPMV constructs is listed above the panels.
Modification of SPMV CP C-terminal extremity impairs SPMV CP and RNA accumulation in planta.

We have reported that SPMV CP promotes the systemic movement of SPMV RNA (Omarov et al. 2005; Qiu and Scholthof 2001) and this activity depends on a functional NARM (unpublished data). However, the contribution of SPMV CP C-terminus is not known. It also is not clear whether SPMV CP is involved in cell-to-cell movement or local accumulation of SPMV RNA and CP. Therefore, in this study, we analyzed SPMV CP and RNA accumulation for each SPMV derivative (Fig. 1A) in the inoculated leaves of plants coinfected with PMV. As for SPMV WT, a substantial amount of $\mathrm{CP}$ accumulated in the inoculated leaves (Fig. 4A, upper panel). In contrast, the $\mathrm{CP}$ titers of mutants $\mathrm{R} 7 / 8$ and R7-12 were reduced by 67 and $80 \%$, respectively, compared with SPMV WT (Fig. 4A, upper panel). Mutants 82F, 130D, and $\triangle \mathrm{C} 6$ displayed levels of CP titers similar to SPMV WT (Fig. 4A, upper panel). Surprisingly, mutations to the C-terminus also severely impaired SPMV CP accumulation in inoculated leaves. In these instances, the CP titers of $\triangle \mathrm{C}$-APS and $\Delta \mathrm{C} 9$ were approximately 40 and $17 \%$ of SPMV WT accumulation, respectively (Fig. 4A, upper panel).

RNA analysis by Northern blot revealed a similar profile for SPMV RNA accumulation of each derivative in the inoculated leaves (Fig. 4A, middle panel). Modification of the N-ARM led to the reduction of SPMV gRNA titer by approximately $80 \%$ for mutants R7/8 and R7-12 compared with SPMV WT (Fig. 4A, middle panel). The gRNA of mutants $82 \mathrm{~F}, 130 \mathrm{D}$, and $\triangle \mathrm{C} 6$ accumulated to a level similar to that of SPMV WT (Fig. 4A, middle panel). However, alterations of the C-terminal extremity of SPMV CP resulted in compromised SPMV RNA accumulation in inoculated leaves. The gRNA titers of mutants $\Delta \mathrm{C}$-APS and $\Delta \mathrm{C} 9$ were decreased by 50 and $75 \%$, respectively (Fig. 4A, middle panel). In addition, modifications of the $\mathrm{N}$ ARM and the C-terminal extremity of SPMV CP caused the de novo generation of SPMV DIs (Fig. 4A, middle panel). Collectively, RNA analysis of inoculated leaves indicates that SPMV CP enhances viral RNA accumulation in inoculated leaves. Above all, this activity is tightly associated with the presence of a functional N-ARM and C-terminal extremity of SPMV CP. In addition, this activity probably is implicated in the process of cell-to-cell movement because replication efficiency in the protoplasts was only modestly affected by alterations in the N-ARM and CTR (Fig. 3A).

In parallel with the above assays on inoculated leaves, protein and RNA analyses also were performed on the systemically infected leaves of proso millet plants inoculated with PMV plus each SPMV derivative shown in Figure 1A. These tests showed that mutations in the N-ARM region of SPMV $\mathrm{CP}$ compromised systemic accumulation of $\mathrm{CP}$, yet constructs $82 \mathrm{~F}, 130 \mathrm{D}$, and $\Delta \mathrm{C} 6$ were barely affected in their CP accumulation (Fig. 4B, upper panel). As in the inoculated leaves (Fig. 4A, upper panel), mutations in the C-terminal extremity also resulted in defective accumulation of $\mathrm{CP}$ for $\triangle \mathrm{C}$-APS and $\Delta \mathrm{C} 9$ in systemic leaves (Fig. 4B, upper panel). Densitometry of gel bands showed that the $\mathrm{CP}$ titer of $\Delta \mathrm{C} 9$ was reduced by approximately $95 \%$ and those of R7/8, R7-12, and $\Delta \mathrm{C}$-APS were reduced by approximately $80 \%$ compared with SPMV WT. Therefore, there is an obvious dosage effect of SPMV CP on symptom severity (Table 1), which is in agreement with its reported function as a pathogenicity factor (Qiu and Scholthof 2001, 2004). RNA analysis revealed that viral RNA accumulation of R7/8, R7-12, $\Delta \mathrm{C}$-APS, and $\Delta \mathrm{C} 9$ in systemic leaves (Fig. 4B, middle panel) displayed the same defects as in inoculated leaves (Fig. 4A, middle panel). These include reduced SPMV gRNA titers and the generation of DIs. Interestingly, we noticed that mutations of the N-ARM (mutants R7/8 and 
R7-12) resulted in the generation of DIs of two different sizes, which often occurs during passage on proso millet (Qiu and Scholthof 2001, 2004). As predicted, mutants 82F, 130D, and $\triangle \mathrm{C6}$ accumulated viral RNA as efficiently as SPMV WT in systemic leaves (Fig. 4B, middle panel).

To exclude the possibility that cis-acting elements in the NARM and C-terminal extremity of SPMV CP had been affected, silent mutations were introduced at the codons of the altered amino acids of mutants R7-12 and $\Delta$ C-APS. In mutant R7-12', the arginine codons of residues $7,8,11$, and 12 were changed from AGG, CGA, CGT, and CGG into AGA, CGT, CGC, and AGG on a full-length infectious SPMV cDNA. Similarly, the original alanine, proline, and serine codons were changed from GCG, CCT, and AGC into GCA, CCG, and TCC in mutant CAPS'. Therefore, these mutations changed the RNA sequence but not the amino acid sequences. Western and Northern blot assays showed that the CP and RNA accumulation was not affected for these two derivatives (Fig. 4C), indicating that it was not the mutation of $c i s$-acting RNA elements but the mutation of amino acids that impaired the in planta accumulation of SPMV RNA and CP. In summary, the capability of SPMV CP in promoting local and systemic SPMV RNA accumulation and maintaining viral RNA integrity requires functional $\mathrm{N}$ ARM and C-terminal extremity regions but not the formation of SPMV virions (Table 1).

\section{Mutations that render SPMV sensitive to high temperature.}

A parallel biological analysis was performed on plants inoculated with PMV plus each SPMV derivative but maintained in the greenhouse with ambient temperatures ranging from 30 to $38^{\circ} \mathrm{C}$. Coinfection of PMV plus SPMV WT, 82F, $130 \mathrm{D}$, or $\Delta \mathrm{C} 6$ still induced typical chlorotic mottle symptoms, with bleaching effects similar to what was shown in Figure 2. However, the symptoms induced by the N-ARM mutants (R7/8 and R7-12) and C-terminal extremity mutants ( $\Delta \mathrm{C}$-APS and $\Delta \mathrm{C} 9$ ) were further attenuated, making them indistinguishable from the mild vein clearing and chlorotic mottle induced by PMV infection alone (data not shown). As expected, the $\mathrm{CP}$

Fig. 4. Capsid protein (CP) and RNA analysis of proso millet plants coinfected with transcripts of Panicum mosaic virus (PMV) and each satellite panicum mosaic virus (SPMV) derivative. Lanes 1 to 8 represent the mixed infections of PMV plus SPMV wild type (WT), R7/8, R7-12, 82F, 130D, $\Delta \mathrm{C} 6, \Delta \mathrm{C}$-APS, or $\triangle \mathrm{C} 9$. A, SPMV CP (upper panel) and RNA (middle panel) accumulation in inoculated leaves of infected plants maintained in the growth chamber $\left(20\right.$ to $\left.25^{\circ} \mathrm{C}\right)$. Immunodetection of SPMV CP is by Western blots using polyclonal specific antibodies. Protein molecular weight markers in kilodaltons $(\mathrm{kDa})$ are indicated on the left side of the panel. Northern blots of total RNA extracted from inoculated leaves were performed using a ${ }^{32} \mathrm{P}$ labeled SPMV cDNA-specific probe. The relative positions of full-length SPMV RNAs and associated defective interfering RNAs (DIs) are indicated on the right. The ethidium-bromide-stained agarose gel is included as the loading control. B, SPMV CP (upper panel) and RNA (middle panel) accumulation in systemic leaves of infected plants maintained in the growth chamber $\left(20\right.$ to $\left.25^{\circ} \mathrm{C}\right)$. Protein and RNA analyses were performed as described in A. Note the DIs of different sizes observed for mutants R7/8 and R7-12. C, Mutations of the N-terminal arginine-rich motif and C-terminal extremity of SPMV CP do not affect cis-acting elements. R7-12' and C-APS' contain codon changes at the same sites as in mutants R7-12 and $\triangle \mathrm{C}$-APS but retain the WT amino acid sequence. Protein (upper panel) and RNA analyses are as described in A. Designation of SPMV derivatives is listed above the blots. D, SPMV CP (upper panel) and RNA (middle panel) accumulation in systemic leaves of infected proso millet plants maintained in the greenhouse (ambient temperature 30 to $38^{\circ} \mathrm{C}$ ). RNA and protein analyses are the same as in A. Note the decreasing amount of $\mathrm{CP}$ and full-length genomic RNA and increasing amount of DIs in R7/8, R7-12, $\Delta \mathrm{C}$-APS, and $\Delta \mathrm{C} 9$ infected proso millet plants. levels of these mutants were either barely detectable (R7/8 and $\Delta \mathrm{C}$-APS) or undetectable (R7-12 and $\Delta \mathrm{C} 9$ ) by Western blot assays (Fig. 4D, upper panel). In contrast, the $\mathrm{CP}$ accumulation of mutants $82 \mathrm{~F}, 130 \mathrm{D}$, and $\Delta \mathrm{C} 6$ was similar to SPMV WT (Fig. 4D, upper panel). The high-temperature-sensitive property also was observed for systemic RNA accumulation of the NARM and C-terminal extremity mutants (Fig. 4D, middle panel). SPMV gRNA of mutant R7/8 was barely detectable and gRNA was not detected for R7-12, $\triangle \mathrm{C}$-APS, and $\Delta \mathrm{C} 9 \mathrm{mu}-$ tants (Fig. 4D, middle panel). However, there was an obvious relative increase in the amount of DIs detected for these SPMV derivatives (Fig. 4D, middle panel) when compared with corresponding infected plants maintained in the growth chamber (Fig. 4B, middle panel). In contrast, DIs were not detected for infections of PMV plus SPMV WT, 82F, 130D, or

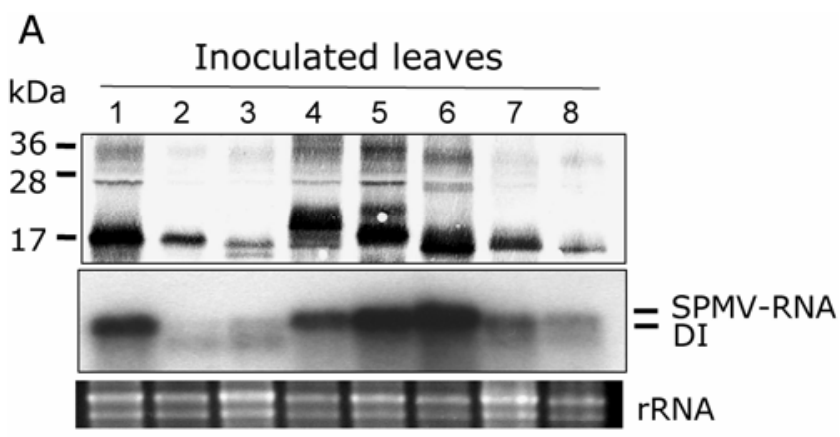

B
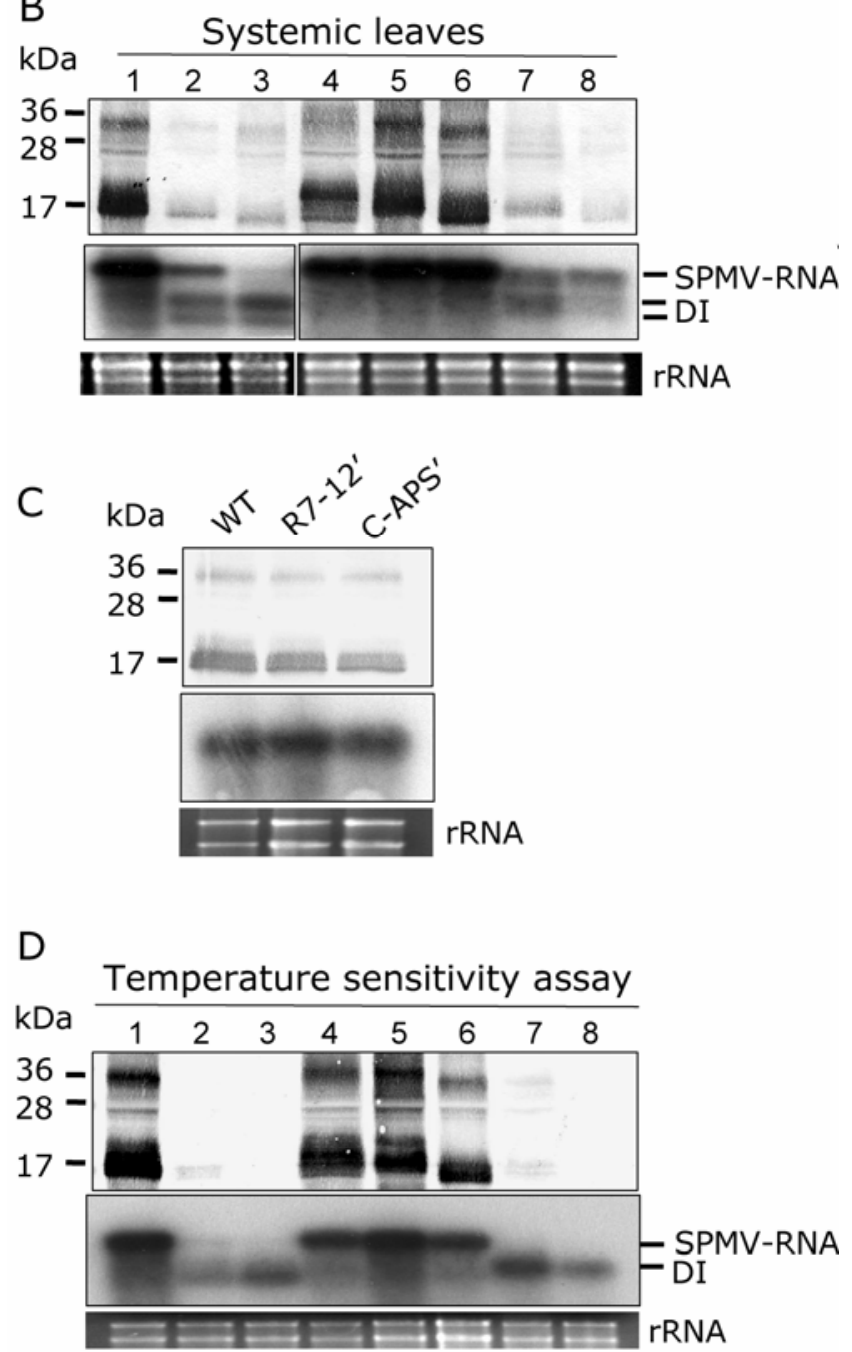
$\triangle$ C6 (Fig. 4D, middle panel) and SPMV RNA accumulation was similarly indistinguishable from infections at 20 to $25^{\circ} \mathrm{C}$ (Fig. 4B, middle panel).

\section{SPMV CP binds both SPMV and PMV gRNAs in vitro.}

It was shown that SPMV CP binds SPMV RNA in a sequence-specific manner (Desvoyes and Scholthof 2000). In this study, we further analyzed the RNA-binding property of SPMV CP by Northwestern blot assays. For this purpose, a series of SPMV CP derivatives were overexpressed in Escherichia coli (Fig. 5A). WT and R7/8 were the corresponding recombinant CPs of SPMV WT and mutant R7/8 (Fig. 1). The NHA SPMV $\mathrm{CP}$ derivative contained the substitution of the amino acid sequence from 4 to 12 with the HA epitope (YPYDVPDYA). The phenotypes of NHA and R7-12 (Fig. 1) were indistinguishable in biological assays on millet plants (data not shown). A, B, C, and $\mathrm{D}$ were recombinant SPMV CP derivatives with different regions deleted, as illustrated (Fig. 5A).

A Western blot was performed first to ensure equal loading of each SPMV CP derivative (Fig. 5B, upper panel). Duplicate membranes were used for the Northwestern blot and probed with $\alpha-{ }_{-}^{32}$ P-UTP labeled SPMV (Fig. 5B, middle panel) and PMV transcripts (Fig. 5B, lower panel). As expected, SPMV WT CP efficiently bound SPMV RNA, which was detected as an autoradiography signal colocalized to the position of SPMV $\mathrm{CP}$ in Western blot (Fig. 5B, middle panel). Surprisingly, SPMV WT CP also bound PMV RNA significantly (Fig. 5B, lower panel). In contrast, the $\mathrm{R} 7 / 8 \mathrm{CP}$ derivative failed to bind detectable levels of SPMV transcript (Fig. 5B, middle panel) though it still was capable of virion assembly (Fig. 3D). Similarly, the NHA CP derivative did not bind SPMV RNA (Fig. 5B, middle panel). Neither the R7/8 CP derivative nor the NHA CP deriva- tive could bind PMV transcripts (Fig. 5B, lower panel), as predicted. $\mathrm{CP}$ derivatives with deletions $(\mathrm{A}, \mathrm{B}, \mathrm{C}$, and $\mathrm{D})$ bound SPMV and PMV transcripts with different affinities, which became weaker with the deleted regions in increasing proximity to the N-ARM (Fig. 5B, upper and middle panels). To rule out the possibility of nonspecific SPMV RNA binding by bacterial proteins, untransformed $E$. coli expressing no SPMV CP was employed as the negative control, and no SPMV or PMV RNAbinding activity was detected (Fig. 5B, upper and lower panels). In summary, even though the N-ARM of SPMV CP plays an essential role in CP:RNA interactions, no such activities are associated with the $\mathrm{C}$-terminal region. Considering that the $\mathrm{C}$ terminal extremity is required for virion assembly (Fig. 3B) and successful RNA accumulation (Fig. 4), these biological activities should be governed by mechanisms other than RNA binding.

\section{DISCUSSION}

SPMV is one of four identified plant satellite viruses (Dodds 1999; Scholthof et al. 1999). The presence of SPMV accelerates the movement and enhances the titer of PMV and exacerbates symptoms (Scholthof 1999). The property of symptom exacerbation was attributed to SPMV CP (Omarov et al. 2005; Qiu and Scholthof 2001), which has been further supported by our observations of dosage effects of SPMV CP on leaf symptom severity (Table1; Figs. 2 and 4B). SPMV CP protein accumulation was compromised to different degrees following modification of the N-ARM (R7/8 and R7-12) and the extreme C-terminus ( $\Delta \mathrm{C}$-APS and $\Delta \mathrm{C} 9$ ) (Fig. 4). Correspondingly, these derivatives were associated with symptom attenuation phenotypes ranging from mild mottle $(\Delta \mathrm{C} 9)$ to moderate chlorotic mottle (R7/8, R7-12, and $\Delta$ C-APS) (Fig. 2).

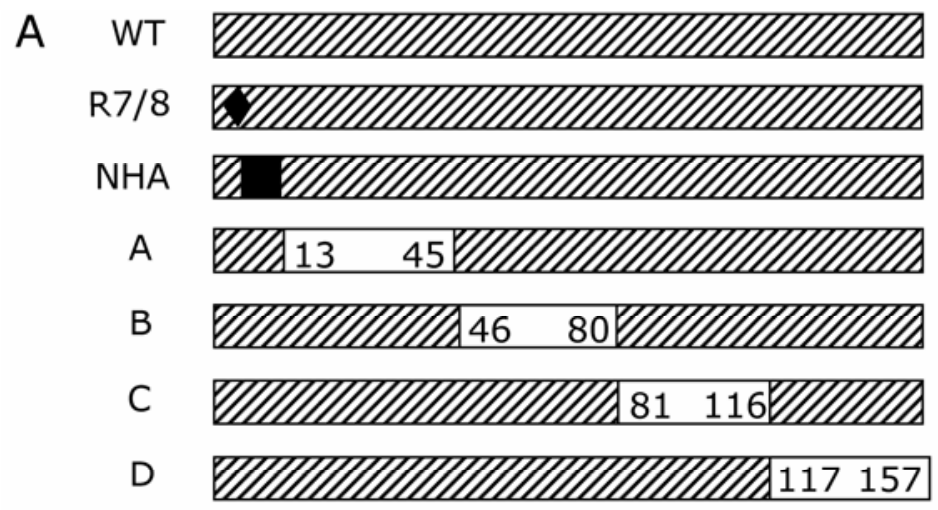

B
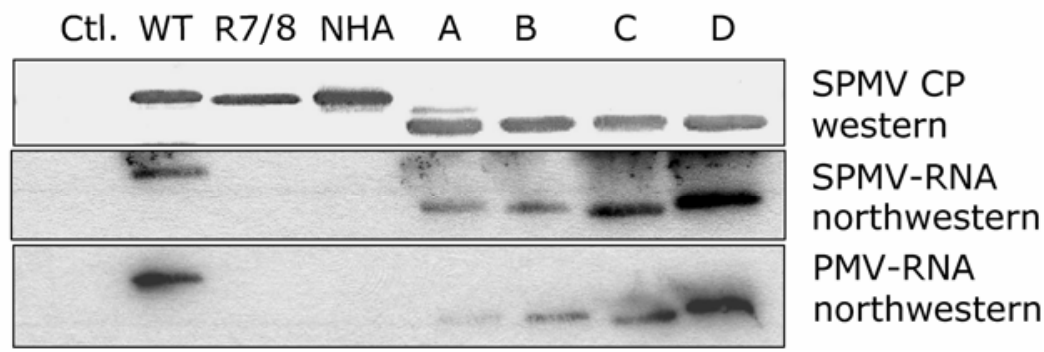

Fig. 5. In vitro RNA binding analysis of satellite panicum mosaic virus (SPMV) capsid protein (CP) derivatives. A, Schematic representation of SPMV CP derivatives analyzed in Northwestern blot assays. The amino acid sequence of R7/8 is the same as that illustrated in Figure 1A. NHA contains the substitution of amino acids from 4 to 12 with an HA epitope (YPYDVPDYA). WT = wild type; A, B, C, and D are four mutants with sequential deletions in the SPMV CP open reading frame from amino acids 13 to 45, 46 to 80, 81 to 116, and 117 to 157 , respectively. B, Northwestern blot analysis of SPMV CP derivatives illustrated in A. All SPMV CP derivatives tested were overexpressed in Escherichia coli and transferred to nitrocellulose membranes followed by probing with ${ }^{32} \mathrm{P}$-labeled SPMV (middle panel) or Panicum mosaic virus (PMV) (lower panel) transcripts. A blot probed with SPMV CP-specific polyclonal antibodies was included to ensure equal loading of proteins for each sample (lower panel). The negative control (Ctl.) represents total proteins extracted from E. coli cells lacking the construct for expressing recombinant SPMV CP. 
In contrast, the mutants $(82 \mathrm{~F}, 130 \mathrm{D}$, and $\Delta \mathrm{C} 6)$ that had a WT-like CP accumulation in infected plants induced the typical chlorotic mottle associated with SPMV+PMV infections (Fig. 2). Interestingly, these mutants were either completely $(82 \mathrm{~F}$ and $130 \mathrm{D})$ or partially $(\Delta \mathrm{C} 6)$ defective in virion formation (Fig. 3B), suggesting that symptom exacerbation is a discrete property. Thus far, the mechanism by which SPMV CP induces pathogenicity remains largely unknown. A cytopathology study showed disruption of mitochondria and tonoplast membranes in plants coinfected with PMV+SPMV (Wilson 1974), which is consistent with our subcellular fractionation study (Omarov et al. 2005). It seems likely that SPMV CP directed to the cell membranes exacerbates symptoms.

The CPs of several plant icosahedral RNA viruses have NARMs that are critical for encapsidation and movement (Kaplan et al. 1998; Rao and Grantham 1996; Sacher and Ahlquist 1989; Schmitz and Rao 1996). The N-ARM of SPMV CP is important for encapsidation, which is in agreement with crystallographic data (Ban and McPherson 1995; Makino et al. 2006). Systemic infection and robust accumulation of RNA in inoculated leaves (Figs. 3B, 4B, and 5B) are additional biologically important features of the SPMV N-ARM (Figs. 3, 4, and 5). Similar effects were observed for the P20 N-ARM of Bamboo mosaic virus satellite RNA (Palani et al. 2006; Tsai et al. 1999).

Although the functional N-ARM-mediated RNA binding is essential for both successful local (Fig. 4A, middle panel) and systemic SPMV RNA accumulation (Fig. 4B, middle panel), it is unlikely that SPMV virions are required for this activity because encapsidation-defective mutants (82F and 130D) were able to enhance SPMV RNA accumulation as SPMV WT in the inoculated leaves and systemic leaves (Fig. 4A and B, middle panels). Therefore, some alternative ribonucleoprotein complexes of SPMV RNA and CP, rather than SPMV virions, must be required for efficient long-distance and cell-to-cell movement. Interestingly, the N-ARM of SPMV CP also mediated the in vitro interactions between SPMV CP and PMV gRNA (Fig. 5B, middle panel). Because SPMV CP is capable of promoting systemic movement, its interactions with PMV RNA may provide some insight about the mechanism of the synergistic interaction between PMV and SPMV (Scholthof 1999).

The SPMV CP has the core structure of an eight-stranded "jelly roll" $\beta$-barrel (Fig. 1C) and the last nine amino acids were predicted as not critical for this core structure (Ban and McPherson 1995). However, we found that the deletion of the last six amino acids (in mutant $\Delta$ C6) caused reduced SPMV virion accumulation and deletions of the three amino acids immediately upstream of this region (mutants $\triangle \mathrm{C}$-APS and $\Delta$ C9) completely abolished virion assembly (Fig. 3B). This indicates that the C-terminal extremity of SPMV CP plays an important auxiliary role during encapsidation to stabilize the virions, possibly by contributing to the quarternary interactions of adjacent subunits. In addition, $\Delta \mathrm{C}$-APS and $\Delta \mathrm{C} 9$ had additional defective phenotypes, resembling N-ARM mutants, with attenuated symptoms and compromised local and systemic CP and RNA accumulation (Fig. 4). These defects cannot be explained merely by the defective SPMV CP:RNA interactions because SPMV CP retained a strong affinity in binding SPMV and PMV gRNA even with a substantial deletion at its C-terminal region (in $\mathrm{CP}$ derivatives $\mathrm{C}$ and $\mathrm{D}$ ) (Fig. 5B). On the other hand, it is likely that the C-terminal region of SPMV CP, especially the three-amino-acid deletion on the $\Delta \mathrm{C}$-APS mutant, is required for interactions with host factors or PMVencoded factors. Such interactions between CPs and other viral factors or host factors have been reported for many plant viruses. For example, interactions between $\mathrm{CP}$ and $2 \mathrm{~b}$ protein of
Tobacco rattle virus participate in its nematode-vectored transmission among host plants (Holeva and MacFarlane 2006); the $\mathrm{CP}$ of Alfalfa mosaic virus (AlMV) activates genome replication by physically interacting with the viral replicase protein (Reichert et al. 2007); and interactions between the CP of Brome mosaic virus and a host factor are absolutely required to initiate infections (Okinaka et al. 2003). We previously reported that SPMV CP interacts with PMV CP in the form of virions, though the biological relevance of such an interaction remains unclear (Omarov et al. 2005).

Another intriguing property of SPMV CP is its ability to inhibit the generation and accumulation of DIs. It is known that the absence of functional SPMV CP triggers the de novo generation and accumulation of DIs (Qiu and Scholthof 2001). However, it is unclear how SPMV CP functions to ensure the synthesis of full-length WT SPMV genome, though this study demonstrates that N-ARM and CTR-extremity mutations result in accumulation of SPMV DIs in inoculated and systemic leaves (Fig. 4A and B, middle panels). A possible explanation is that SPMV CP interacts with the RNA template via its $\mathrm{N}$ $\mathrm{ARM}$ and with the replication machinery via its C-terminal extremity to bond them more tightly to ensure the synthesis of full-length progeny RNAs. Therefore, the impairment of SPMV CP:RNA interactions or possible CP interactions with the viral replicase complex would lead to decreased processivity by the PMV replicase and the rapid accumulation of SPMV DIs.

The importance of CP in replication has been reported for alfamoviruses and ilarviruses (Bol 1999; Choi et al. 2003; Houwing and Jaspars 1993). A recent study reveals that AlMV $\mathrm{CP}$ increases the affinity between template RNA and AlMV RNA polymerase by interacting with them simultaneously (Reichert et al. 2007). Therefore, because SPMV mutants 82F and 130D retained their functional N-ARM and the C-terminal domains, they may be competent to interact with template RNA and the replication machinery to inhibit DI accumulation, in spite of being compromised for virion assembly (Fig. 3B). Alternatively, SPMV CP may simply interact with cognate RNAs to prevent their possible recognition by a cellular RNA surveillance pathway such as posttranscriptional gene silencing (Voinnet et al. 1999). However, it was perplexing that no DIs were detected for mutants R7/8, R7-12, $\Delta$ C-APS, and $\Delta \mathrm{C} 9$ in transfected foxtail millet protoplasts, nor did these mutants display any obvious defects of replication (Fig. 3A). One possible explanation is that transfected foxtail millet protoplasts can be maintained for only approximately $48 \mathrm{~h}$. This may represent much less time than required for de novo generation of DIs in nature or their detection. Alternatively, DIs may be selected for during cell-to-cell movement in millet plants in the absence of functional SPMV CP.

The biological importance of the N-ARM and the extreme CTR also was reflected by the temperature-sensitivity phenotype observed for mutants R7/8, R7-12, $\Delta \mathrm{C}$-APS, and $\Delta \mathrm{C} 9$. When the infected plants were maintained in the greenhouse with ambient temperatures of 30 to $38^{\circ} \mathrm{C}$, we observed more compromised CP accumulation (Fig. 4D, upper panel), an increasing amount of DIs, and the absence of full-length SPMV gRNA (Fig. 4D, middle panel) for mutants R7/8, R712, $\Delta \mathrm{C}$-APS, and $\Delta \mathrm{C} 9$ compared with corresponding infected plants in the growth chamber $\left(20\right.$ to $\left.25^{\circ} \mathrm{C}\right)$. One explanation is that the faster growth rate of proso millet plants in the greenhouse may enable the host plants to outpace the infection front of these movement-defective mutants to keep the new tissues free of the full-length parental SPMV RNA. Alternatively but not exclusively, the defective interactions of the mutated proteins of R7/8, R7-12, $\triangle \mathrm{C}$-APS, and $\triangle \mathrm{C} 9$ with SPMV RNA or other factors might become even less stable and result in the high-temperature-sensitive phenotype. 
Both the N-ARM and the extreme CTR of SPMV CP are of crucial importance for cell-to-cell and long-distance movement of SPMV RNA and for inhibiting the generation of DIs. In contrast, SPMV virions are not essential for these activities (Table 1). This observation raises an open question: why does SPMV CP maintain its ability to encapsidate SPMV RNA if virions do not provide an obvious advantage for SPMV? From an evolutionary perspective, this property of virion assembly should be quickly lost in the absence of positive selective pressures due to mutations resulting from the error-prone nature of viral RNA polymerase. One possible function of SPMV virion assembly is to serve as the long-term reservoir of inoculum for host-to-host transmission under natural conditions (perhaps vectored by a chytrid-like fungus). This hypothesis is supported by the observation that Tobacco mosaic virus virions have been reported to remain infectious in nonsterile extracts at room temperature for at least 50 years whereas its gRNA is no more stable than other single-stranded RNAs (Silber and Burk 1965). In addition, the interactions between SPMV and PMV virions (Omarov et al. 2005) may lead to the uncoating of SPMV and PMV RNAs in close proximity to each other when they enter uninfected host cells. This would provide SPMV RNA a greater likelihood of being recognized by the PMV replicase complex for multiplication.

\section{MATERIALS AND METHODS}

\section{Host plants and inoculation.}

Proso millet plants (P. miliaceum cv. "Sunup") were grown in a growth chamber $\left(25^{\circ} \mathrm{C}, 14 \mathrm{~h}\right.$ of light and $20^{\circ} \mathrm{C}, 10 \mathrm{~h}$ of darkness) or in the greenhouse (temperature range of 30 to $38^{\circ} \mathrm{C}$ ). Plants were mechanically rub inoculated with a mixture of equal volumes of uncapped RNA transcripts (SPMV and PMV) and RNA inoculation buffer $\left(0.05 \mathrm{M} \mathrm{K}_{2} \mathrm{HPO}_{4}, 0.05 \mathrm{M}\right.$ glycine, $1 \%$ bentonite, and $1 \%$ celite, $\mathrm{pH} 9.0)$ at the three-leaf stage. Visual symptoms of systemically infected leaves were monitored and compared for 3 weeks postinoculation. Each biological assay was repeated three times. Protoplasts were isolated from foxtail millet (Setaria italica cv. German R) seedlings 2 weeks after germination in a growth chamber. The preparation and transfection of foxtail millet protoplasts were performed as described before (Scholthof et al. 1993) except that millet protoplasts were centrifuged at $210 \times g$ instead of $70 \times g$ in a clinical centrifuge (International Equipment Co., Needham Heights, MA, U.S.A.). Approximately $5 \times 10^{6}$ protoplasts were transfected with PMV RNA transcripts alone or in combination with in vitro-synthesized SPMV transcripts derived from either the type strain or mutant cDNA clones through a polyethylene glycol procedure (Scholthof et al. 1993). The transfected protoplasts were incubated in the growth cabinet $\left(28^{\circ} \mathrm{C}, 14 \mathrm{~h}\right.$ of light and $24^{\circ} \mathrm{C}, 10 \mathrm{~h}$ of darkness) for approximately $48 \mathrm{~h}$ prior to the extraction of total RNA or protein.

\section{Construction of SPMV mutant cDNA.}

The QuikChange kit (Stratagene, La Jolla, CA, U.S.A.) was used to make R7/8, R7-12, 130D, $\Delta \mathrm{C} 6$, and $\Delta \mathrm{C} 9$ via sitedirected mutagenesis. The forward primer for R7/8 was $5^{\prime}$-ctaa gggtaccagCGCatctaatcgtcggg- $3^{\prime}$ and reverse was $5^{\prime}$-cccgacgatt agatGCGctggtaccttag-3'. For R7-12, the primers were forward, 5'-agcgcatctaatcTCTcggcgggctcc-3' and reverse, 5'-ggag cccgccgAGAgattagttgcgct- $3^{\prime}$. The primers to generate mutant $130 \mathrm{D}$ were forward, 5'-gacggactcgtgGAtaccaagggtga-3' and reverse, $5^{\prime}$-tcacccttggtaTCcacgagtccgtc- $3^{\prime}$. All mutated nucleotides are in capitals and affected codons are underlined. The primers to create mutant $\Delta \mathrm{C} 6$ were forward, 5'-taggctggcgect TAAagcgagcttcag-3' and reverse, 5'-ctgaagctcgct TTAaggcgcc agccta- $3^{\prime}$. The primers to create mutant $\Delta \mathrm{C} 9$ were forward, $5^{\prime}$ - acgggttgctttagg TAActggcgectagcgag- $3^{\prime}$ and reverse, $5^{\prime}$-ctcgcta ggcgccagTTAcctaaagcaacccgt- $3^{\prime}$. The premature stop codons are in bold uppercase. Deletion mutants (A, B, C, and D), insertion mutant $(82 \mathrm{~F})$, and substitution mutant (NHA) were obtained by a modified recombination polymerase chain reaction protocol (Qi and Scholthof 2008). Primers to create $\Delta \mathrm{C}$ APS were designed using the forward primer 5'-ttaggctggcgc ttcagtcttcataaagtatc- $3^{\prime}$ and reverse primer $5^{\prime}$-ctgaagctccagcctaa agcaacccgtaacaat- $3^{\prime}$. Primers to create silent mutant R7-12' and C-APS' were designed following the principle described by Zheng and associates (2004). The primers for R7-12' were forward, 5'-agacgttctaatcgcagggcgggcgccegggcta-3' and reverse, 5'-cctgcgattagaacgtctggtacccttagg-3'. Mutant C-APS' was generated with forward primer 5'-aggttagcaccotccgagcttca gtcttcttaa-3' and reverse primer 5'-ctcggacggtgctaacctaaagcaa cccgtaaca-3'. Complimentary regions of the primers are shown in lowercase italicized letters and the mutated nucleotides in bold typeface.

\section{In vitro transcription and translation.}

A PMV cDNA construct linearized with EcoICRI and SPMV cDNA construct or mutated SPMV cDNA constructs linearized with $B g l I I$ were used as templates for in vitro transcription (Turina et al. 1998; Scholthof 1999). In vitro translation was carried out using a coupled transcription-translation wheat germ extract system (Promega Corp., Madison, WI, U.S.A.).

\section{RNA and protein analysis.}

Total RNA from $300 \mathrm{mg}$ of inoculated or systemically infected leaves of millet plants was extracted at 14 days postinoculation (dpi). Symptomatic leaf tissues were pulverized in $1 \mathrm{ml}$ of ice-cold extraction buffer $(100 \mathrm{mM}$ Tris- $\mathrm{HCl}$ [pH 8.0], $1 \mathrm{mM}$ ETDA, $0.1 \mathrm{M} \mathrm{NaCl}$, and $1 \%$ sodium dodecyl sulfate [SDS]) and extracted twice with phenol-chloroform $(1: 1, \mathrm{vol} / \mathrm{vol})$ at room temperature. Total RNA was precipitated with $8 \mathrm{M}$ lithium chloride $(1: 1, \mathrm{vol} / \mathrm{vol})$ at $4^{\circ} \mathrm{C}$ for $30 \mathrm{~min}$. The resulting pellets were washed with $70 \%$ ethanol, resuspended in RNase-free distilled water, and used for Northern blot hybridization. Approximately $5 \mu \mathrm{g}$ of total plant RNA was electrophoretically separated in $1 \%$ agarose gels and transferred to nylon membranes (Osmonics, Westborough, MA, U.S.A.). SPMV RNAs were detected by hybridization with $\alpha-\left[{ }^{32} \mathrm{P}\right]-$ dCTP-labeled SPMV-specific probes. Protein samples were separated by SDS-polyacrylamide gel electrophoresis in $15 \%$ polyacrylamide gels and transferred to nitrocellulose membranes (Osmonics). The SPMV CP or PMV CP antibodies were applied at a dilution of 1:2,000. Alkaline phosphatase conjugated to goat anti-rabbit antiserum (Sigma-Aldrich, St. Louis) was used as a secondary antibody at a dilution of $1: 1,000$ and the immune complexes were visualized by the addition of nitroblue tetrazolium and 5-bromo-4-chloro-3indolyl phosphate as described previously (Omarov et al. 2005. Densitometric analysis of RNA and CP titers were conducted using NIH ImageJ.

\section{Minipurification of virions and encapsidation assays.}

Symptomatic leaf tissue $(0.5 \mathrm{~g})$ was ground in $2 \mathrm{ml}$ of extraction buffer $(0.2 \mathrm{M}$ sodium acetate, $\mathrm{pH} 5.2)$. The homogenate then was incubated at $37^{\circ} \mathrm{C}$ for $30 \mathrm{~min}$ to utilize the endogenous plant RNases to degrade any unprotected RNAs, including host cell RNA and unencapsidated viral RNAs. The extract then was centrifuged at $10,000 \mathrm{rpm}$ and $4{ }^{\circ} \mathrm{C}$ for 10 min. The supernatant was transferred to an empty tube and the virions were precipitated on ice for $30 \mathrm{~min}$ in the presence of $12 \%$ polyethylene glycol (PEG)-8000 and $300 \mathrm{mM} \mathrm{NaCl}$ ( $\mathrm{PEG}-\mathrm{NaCl})$. The virions then were pelleted by centrifugation 
at $10,000 \mathrm{rpm}$ and $4^{\circ} \mathrm{C}$ for $10 \mathrm{~min}$ and resuspended in $0.05 \mathrm{M}$ sodium acetate $(\mathrm{pH} 5.5)$ for a second precipitation overnight at $4^{\circ} \mathrm{C}$ with PEG-NaCl, as described above. The final virion pellet was resuspended in $50 \mu \mathrm{l}$ of $0.05 \mathrm{M}$ sodium acetate $(\mathrm{pH}$ 5.5 ) and $5 \mu \mathrm{l}$ of resuspended virions was resolved on a $1 \%$ Tris-glycine agarose gel in $2 \times$ Tris-glycine buffer $(10 \mathrm{mM}$ Tris [pH 8.0] and $76 \mathrm{mM}$ glycine). Whole virions were transferred to nylon membrane for the SPMV-specific RNA hybridization assays.

\section{In vitro SPMV and PMV RNA-binding assays.}

All SPMV CP derivatives were overexpressed in E. coli BL21(DE3) cells (Stratagene) using a pDEST17-based vector (Invitrogen, Carlsbad, CA, U.S.A.). A 1.5-ml culture of induced $E$. coli BL21(DE3) cells was pelleted and boiled in $2 \%$ SDS-sample buffer, electrophoresed through $15 \%$ polyacrylamide gels, and transferred to nitrocellulose membrane. The membrane then was blocked for $2 \mathrm{~h}$ at room temperature (RT) in binding buffer (10 mM Tris- $\mathrm{HCl}$ [pH 7], $1 \mathrm{mM}$ EDTA, and $1 \times$ Denhardt's reagent] containing $300 \mathrm{mM} \mathrm{NaCl}$ and total RNA extracted from healthy plants at $25 \mu \mathrm{g} / \mathrm{ml}$. The $\left[{ }^{32} \mathrm{P}\right]-$ labeled SPMV RNA probe was added and incubated with the blot for $2 \mathrm{~h}$ at RT. The membrane was washed three times with binding buffer plus $300 \mathrm{mM} \mathrm{NaCl}$ and exposed to X-ray film overnight, as described previously (Desvoyes and Scholthof 2000).

\section{ACKNOWLEDGMENTS}

We thank H. B. Scholthof and R. T. Omarov for critical review and discussion of the manuscript. This research was funded by a grant to K.-B. G. Scholthof from the Texas Higher Education Coordinating Board Advanced Technology Program.

\section{LITERATURE CITED}

Ban, N., and McPherson, A. 1995. The structure of satellite panicum mosaic virus at 1.9. A resolution. Nat. Struct. Biol. 2:882-890.

Bol, J. F. 1999. Alfalfa mosaic virus and ilarviruses: Involvement of coat protein in multiple steps of the replication cycle. J. Gen. Virol. 80:10891102.

Cabrera, O., and Scholthof, K.-B. G. 1999. The complex viral etiology of St. Augustine decline. Plant Dis. 83:902-904.

Choi, J., Kim, B. S., Zhao, X., and Loesch-Fries, S. 2003. The importance of Alfalfa mosaic virus coat protein dimers in the initiation of replication. Virology 305:44-49.

Desvoyes, B., and Scholthof, K.-B. G. 2000. RNA:protein interactions associated with satellites of Panicum mosaic virus. FEBS (Fed. Eur. Biochem. Soc.) Lett. 485:25-28.

Dodds, J. A. 1999. Satellite tobacco mosaic virus. Curr. Top. Microbiol. Immunol. 239:145-157.

Holeva, R. C., and MacFarlane, S. A. 2006. Yeast two-hybrid study of Tobacco rattle virus coat protein and $2 \mathrm{~b}$ protein interactions. Arch. Virol. 151:2123-2132.

Houwing, C. J., and Jaspars, E. M. 1993. Coat protein stimulates replication complexes of alfalfa mosaic virus to produce virion RNAs in vitro. Biochimie 75:617-621.

Kaplan, I. B., Zhang, L., and Palukaitis, P. 1998. Characterization of cucumber mosaic virus. V. Cell-to-cell movement requires capsid protein but not virions. Virology 246:221-231.

Makino, D. L., Day, J., Larson, S. B., and McPherson, A. 2006. Investigation of RNA structure in satellite panicum mosaic virus. Virology 351:420-431.

Masuta, C., Zuidema, D., Hunter, B. G., Heaton, L. A., Sopher, D. S., and Jackson, A. O. 1987. Analysis of the genome of satellite panicum mosaic virus. Virology 159:329-338.

Okinaka, Y., Mise, K., Okuno, T., and Furusawa, I. 2003. Characterization of a novel barley protein, $\mathrm{HCP} 1$, that interacts with the Brome mosaic virus coat protein. Mol. Plant-Microbe Interact. 16:352-359.

Omarov, R. T., Qi, D., and Scholthof, K.-B. G. 2005. The capsid protein of satellite panicum mosaic virus contributes to systemic invasion and interacts with its helper virus. J. Virol. 79:9756-9764.

Palani, P. V., Kasiviswanathan, V., Chen, J. C. F., Chen, W., Hsu, Y-.H., and Lin, N-.S. 2006. The arginine-rich motif of Bamboo mosaic virus satellite RNA-encoded p20 mediates self-interaction, intracellular targeting, and cell-to-cell movement. Mol. Plant-Microbe Interact. 19:758-767.

Qi, D. 2007. Molecular biology study of satellite panicum mosaic virus capsid protein. Ph.D. dissertation,, Texas A\&M University, College Station, TX, U.S.A.

Qi, D., and Scholthof, K.-B. 2008. A one-step PCR-based method for rapid and efficient site-directed fragment deletion, insertion, and substitution mutagenesis. J. Virol. Meth. 149:85-90.

Qiu, W., and Scholthof, K.-B. G 2000. In vitro- and in vivo-generated defective RNAs of satellite panicum mosaic virus define cis-acting RNA elements required for replication and movement. J. Virol. 74:22472254.

Qiu, W., and Scholthof, K.-B. G. 2001. Genetic identification of multiple biological roles associated with the capsid protein of satellite panicum mosaic virus. Mol. Plant-Microbe Interact. 14:21-30.

Qiu, W., and Scholthof, K.-B. G. 2004. Satellite panicum mosaic virus capsid protein elicits symptoms on a nonhost plant and interferes with a suppressor of virus-induced gene silencing. Mol. Plant-Microbe Interact. 17:263-271.

Rao, A. L. N., and Grantham, G. L. 1996. Molecular studies on bromovirus capsid protein. II. Functional analysis of the amino-terminal arginine-rich motif and its role in encapsidation, movement, and pathology. Virology 226:294-305.

Reichert, V. L., Choi, M., Petrillo, J. E., and Gehrke, L. 2007. Alfalfa mosaic virus coat protein bridges RNA and RNA-dependent RNA polymerase in vitro. Virology 364:214-226.

Sacher, R., and Ahlquist, P. 1989. Effects of deletions in the N-terminal basic ARM of brome mosaic virus coat protein on RNA packaging and systemic infection. J. Virol. 63:4545-4552.

Schmitz, I., and Rao, A. L. N. 1996. Molecular studies on bromovirus capsid protein. I. Characterization of cell-to-cell movement-defective RNA3 variants of brome mosaic virus. Virology 226:281-293.

Scholthof, H. B., Morris, T. J., and Jackson, A. O. 1993. The capsid protein gene of tomato bushy stunt virus is dispensable for systemic movement and can be replaced for localized expression of foreign genes. Mol. Plant-Microbe Interact. 6:309-322.

Scholthof, K.-B. G. 1999. A synergism induced by satellite panicum mosaic virus. Mol. Plant-Microbe Interact. 12:163-166.

Scholthof, K.-B. G., Jones, R. W., and Jackson, A. O. 1999. Biology and structure of plant satellite viruses activated by icosahedral helper viruses. Curr. Top. Microbiol. Immunol. 239:123-143.

Silber, G., and Burk, L. G. 1965. Infectivity of tobacco mosaic virus stored for fifty years in extracted, 'unpreserved' plant juice. Nature 206:740-741.

Tsai, M-.S., Hsu, Y-.H., and Lin, N-.S. 1999. Bamboo mosaic potexvirus satellite RNA (satBaMV RNA)-encoded p20 protein preferentially binds to satBaMV RNA. J. Virol. 73:3032-3039.

Turina, M., Maruoka, M., Monis, J., Jackson, A. O., and Scholthof, K.-B. G. 1998. Nucleotide sequence and infectivity of a full-length cDNA clone of panicum mosaic virus. Virology 241:141-155.

Turina, M., Desvoyes, B., and Scholthof, K.-B. G. 2000. A gene cluster encoded by panicum mosaic virus is associated with virus movement. Virology 266:120-128.

Voinnet, O., Pinto, Y. M., and Baulcombe, D. C. 1999. Suppression of gene silencing: A general strategy used by diverse DNA and RNA viruses of plants. Proc. Natl. Acad. Sci. U.S.A. 96:14147-14152.

Wilson, W. J. 1974. A histological and ultrastructural study of the St. Augustinegrass strain of panicum mosaic virus in resistant and susceptible St. Augustinegrass and red Siberian millet. Ph.D. dissertation, Texas A\&M University, College Station, TX, U.S.A.

Zheng, L., Baumann, U., and Reymond, J. L. 2004. An efficient one-step site-directed and site-saturation mutagenesis protocol. Nucleic Acids Res. 32:e115.

\section{AUTHOR-RECOMMENDED INTERNET RESOURCE}

National Institutes of Health ImageJ website: rsb.info.nih.gov/ij/index.ntml 